Thorax (1971), 26, 449.

\title{
Successful prolonged resuscitation after open heart surgery
}

\author{
H. STEIN, S. RUBIN, G. MERIN, S. COTEV, and J. B. BORMAN \\ Departments of Thoracic and Cardiovascular Surgery and Anaesthetics, Hebrew University-Hadassah \\ Medical School and Hadassah University Hospital, Jerusalem, Israel
}

\begin{abstract}
Five selected cases of successful prolonged resuscitation (up to 16 hours) after open heart surgery are presented. Four had undergone prosthetic valve insertion, two being double replacements. External cardiac massage did not produce any demonstrable damage to the heart or the implanted valve prostheses, the competent prostheses probably assuring the haemodynamic effectiveness of the massage. Intermittent positive pressure breathing via an endotracheal tube providing $100 \%$ oxygen was begun immediately in all cases. The continuous monitoring of blood pressure through an intra-arterial cannula during resuscitation was of great value. It indicated the minimum amount of force that had to be applied to obtain satisfactory perfusion and enabled frequent arterial blood sampling for $\mathrm{pH}$ and blood gas analyses. Thus acidosis could rapidly and effectively be corrected. Comment is made upon the use of bretylium tosylate and chlorpromazine during resuscitation. The value of the continuous presence of a physician at the bedside of patients after open heart surgery and an aggressive, stubborn approach to cardiopulmonary resuscitation as long as vital signs are present is stressed.
\end{abstract}

Closed chest cardiac massage was first described by Kouwenhoven, Jude, and Knickerbocker (1960). Many authors have since furthered the knowledge and understanding of the management of cardiac arrest, and large series describing resuscitation have been published (Ayers and Doyle, 1962; Gilston, 1965; Head, Hudson, Head, and Head, 1962; Jude, Kouwenhoven, and Knickerbocker, 1961; Kaplan and Knott, 1964; Klassen, Broadhurst, Peretz, and Johnson, 1963; Lawrence, Haley, and Gillies, 1964; Lillehei, Lavadia, DeWall, and Sellers, 1965; Saphir, 1968). Most reporters stress the relationship between the length of the resuscitative effort and the prognosis. A fairly accurate prognosis of the resuscitation can be made after 30 minutes of external cardiac massage and artificial ventilation without the return of a spontaneous peripheral pulse (Kaplan and Knott, 1964), but individual reports of prolonged successful resuscitations (Lillehei et al., 1965) preclude dogmatic generalizations. The reported survival rate for those patients who needed recurrent attempts at resuscitation varies from low (Ayers and Doyle, 1962 ; Gilston, 1965) to none (Saphir, 1968). However, cardiac resuscitation in the immediate postoperative period following open heart surgery is rarely discussed in the English literature (Gilston, 1965; Jude et al., 1961).

This report describes five selected cases from a series in whom cardiac arrest in the post open heart surgery period was successfully treated by prolonged or repeated closed chest resuscitation (Table I). Four of these patients had undergone prosthetic valve replacement.

\section{CASE REPORTS}

CASE 1 A 30-year-old woman underwent mitral and tricuspid valve replacement for severe rheumatic mitral and tricuspid stenosis and incompetence. Preoperatively she was in chronic congestive cardiac failure and in atrial fibrillation. The valves were replaced by Kay-Shiley disc valves. In order to wean her off the pump an isoproterenol drip $(0.4 \mathrm{mg}$ in $100 \mathrm{ml}$ glucose $5 \%, 4$ drops $/ \mathrm{min}$ ) was necessary for a period of $\mathbf{3 0}$ minutes. Following this, surgery progressed unremarkably.

Sixteen hours postoperatively she suddenly developed ventricular fibrillation. At the time she was ventilated by a respirator via a nasotracheal tube. External cardiac massage was immediately begun and $100 \%$ oxygen was used for intermittent positive pressure breathing (I.P.P.B.). Repeated attempts at DC defibrillation were inffective. Resuscitative measures continued, and throughout the whole period the patient 
T A B L E

CLINICAL DETAILS OF PATIENTS WHO SURVIVED PROLONGED RESUSCITATION

\begin{tabular}{|c|c|c|c|c|c|c|}
\hline Case & Age & Sex & Operation & $\begin{array}{l}\text { Time of Cardiac } \\
\text { Arrest after } \\
\text { Surgery }\end{array}$ & $\begin{array}{c}\text { Duration of } \\
\text { Resuscitation }\end{array}$ & $\begin{array}{l}\text { Time of } \\
\text { Follow-up } \\
(\mathrm{mth})\end{array}$ \\
\hline 1 & 30 & $\mathbf{F}$ & Mitral plus tricuspid valve replacement & $16 \mathrm{hr}$ & $2 \mathrm{hr}$ & 24 \\
\hline 2 & 52 & $\mathbf{F}$ & Mitral plus tricuspid valve replacement & $\begin{array}{l}10 \mathrm{hr} ; 16 \text { days; } \\
19 \text { days }\end{array}$ & $15 \min _{20 \mathrm{~min}} 30 \mathrm{~min} ;$ & $\begin{array}{l}18 \text { then } \\
\text { died in CHF }\end{array}$ \\
\hline 3 & 24 & $\mathbf{F}$ & Mitral valve replacement & $7 \mathrm{hr}$ & $\begin{array}{c}4 \mathrm{hr} \\
\text { intermittently }\end{array}$ & 18 \\
\hline 4 & 54 & $\mathbf{F}$ & Open valvotomy & $28 \mathrm{hr}$ & $2 \mathrm{hr}$ & 18 \\
\hline 5 & 31 & $\mathbf{F}$ & Mitral valve replacement & 36 days & $\begin{array}{c}16 \mathrm{hr} \\
\text { intermittently }\end{array}$ & 12 \\
\hline
\end{tabular}

actively resisted external cardiac massage, being fully conscious. Blood pressure was monitored continuously via an intra-arterial cannula (radial artery) and displayed on an oscilloscope. Systolic pressure was maintained at $100 \mathrm{mmHg}$. The electrocardiogram was similarly monitored. A total of $223 \mathrm{mEq}$ sodium bicarbonate, $500 \mathrm{ml}$ trometamol (THAM) $0.3 \mathrm{M}$, and $1 \mathrm{~g}$ dicalcium chloride were given intravenously.

As no response to defibrillation was obtained, 250 $\mathrm{mg}$ bretylium tosylate were given intravenously. External cardiac massage was continued throughout. Twenty minutes later an identical dose was given intramuscularly. Two hours after the onset of ventricular fibrillation the heart reverted spontaneously to a slow supraventricular rhythm. The patient was thus able to maintain a systolic blood pressure of $100 \mathrm{mmHg}$ and the cardiac massage was discontinued. The patient was awake. Her urinary output was adequate. Bretylium therapy was continued, $250 \mathrm{mg}$ being administered intramuscularly every six hours. Eight hours after the first episode of ventricular fibrillation another short run of ventricular fibrillation reverted spontaneously to atrial fibrillation. Twenty-four hours after resuscitation the patient was in sinus rhythm.

Except for mild paradoxical movement of the anterior chest, the patient's further recovery was uneventful. She was discharged 21 days postoperatively. She is in excellent condition at present, 24 months after surgery.

CASE 2 A 52-year-old woman suffering from rheumatic mitral and tricuspid valve disease was admitted to hospital in intractable congestive heart failure and atrial fibrillation. At surgery the damaged mitral and tricuspid valves (both of them stenotic and insufficient) were replaced by Kay-Shiley disc valves. Both an isoproterenol infusion $(0.4 \mathrm{mg}$ in $100 \mathrm{ml} 5 \%$ glucose) and intravenous calcium chloride were administered in order to help wean the patient off the cardiopulmonary bypass. The heart was paced by atrial electrodes to override a nodal rhythm.

Ten hours postoperatively, following a progressive drop of blood pressure and rise of central venous pressure and a radiograph showing widening of the mediastinal shadow, the patient was reoperated for $ᄋ$ suspected cardiac tamponade. No haemopericardium was found, however. At the conclusion of this pro- $c$ cedure asystole of the heart occurred. The chest was rapidly reopened and 15 minutes of direct cardiac $\vec{\varphi}$ massage was needed for the heart to regain spon- $\varphi$ taneous contractions. The patient recovered slowly. thereafter. Sixteen days postoperatively atrial fibrillation was electrically converted to a regular sinus rhythm. To maintain this rhythm a daily dose of $30 \mathrm{mg}$ propranolol was recommended. However, after the administration of the first $20 \mathrm{mg}$, progressive $\frac{\otimes}{\varnothing}$ bradycardia supervened, terminating in asystole $\varnothing$ (Fig. 1). The patient responded to external massage, $\overrightarrow{0}$ I.P.P.B., isoproterenol drip, and $89.2 \mathrm{mEq} \mathrm{NaHCO}_{3} 3$ intravenously. A short run of ventricular flutter was terminated by one DC defibrillating shock (Fig. 2). Various supraventricular and ventricular extrasystoles were observed (Fig. 3) until a sinus rhythm of $60 / \mathrm{min}$

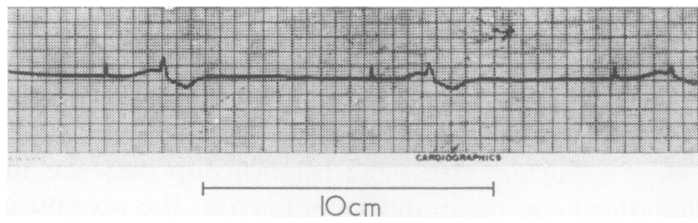

FIG. 1. Pronounced bradycardia prior to asystole.

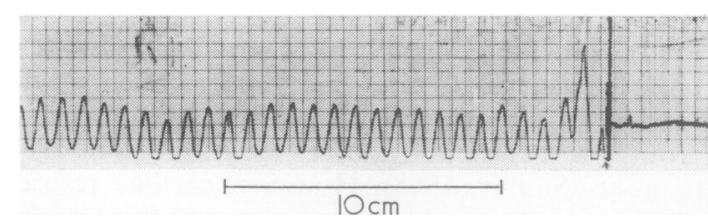

FIG. 2. A bout of ventricular flutter. 


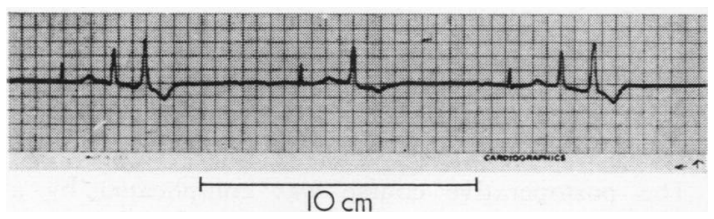

FIG. 3. Ectopic beats recorded in the post-asystole phase.

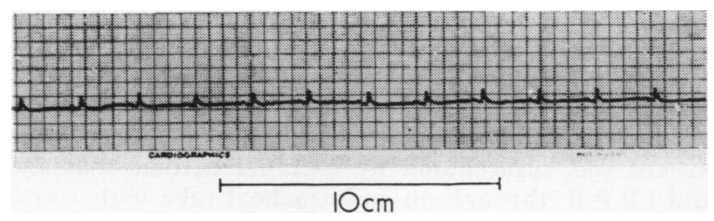

FIG. 4. Sinus rhythm after successful resuscitation.

was obtained (Fig. 4). Complete consciousness returned. Quinidine, $0.3 \mathrm{~g}$ thrice daily, and digoxin, $0.25 \mathrm{mg}$ twice daily, were orally administered. Three days later ventricular fibrillation suddenly developed. Once again resuscitative measures were instituted.
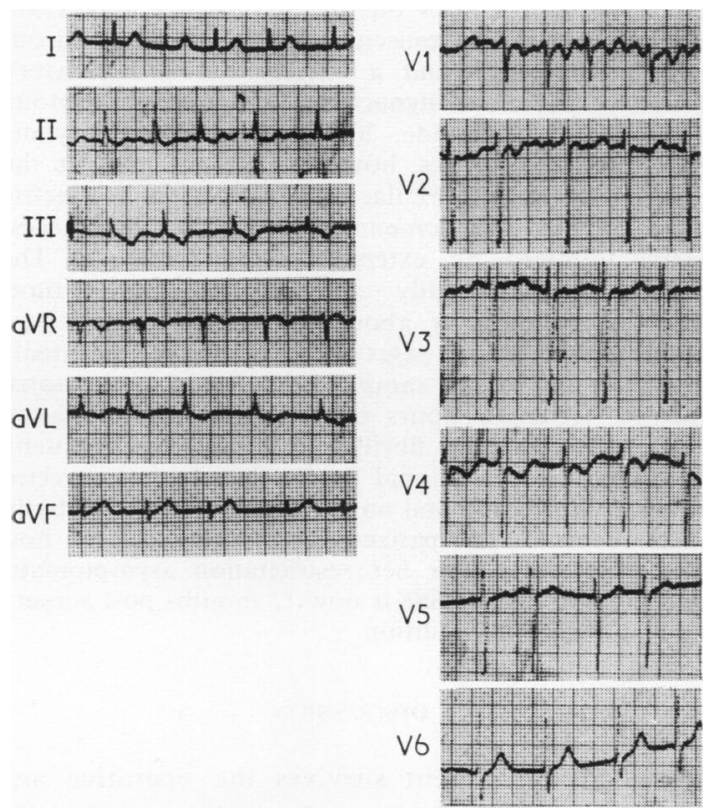

FIG. 5. Atrial fibrillation with a ventricular rate of $88 / \min$.
Within 20 minutes the heart was beating in atrial fibrillation with a ventricular rate of $88 / \mathrm{min}$ (Fig. 5). Consciousness returned after eight days. Following a further period of convalescence the patient was discharged. Physically she remained well for 15 months postoperatively, but mentally she was somewhat euphoric. Her condition thereafter deteriorated and she died one and a half years after surgery in congestive cardiac failure. Necropsy revealed gross endocardial fibrosis.

CASE 3 A 24-year-old woman suffering from rheumatic heart disease, with mitral stenosis and insufficiency in the stage of grade IV $^{1}$ incapacitation with extreme pulmonary hypertension, was admitted to hospital for surgery. The damaged mitral valve was replaced by an aortic xenograft.

At the end of operation complete A-V block was noted and the heart was paced by a direct ventricular pacemaker. Four hours after surgery short runs of ventricular tachycardia and flutter appeared intermittently. Hypokalaemia and hyperventilation were corrected with no effect on the bouts of ventricular tachycardia, and it was therefore decided to give the patient $5 \mathrm{mg} / \mathrm{kg}$ bretylium tosylate intramuscularly. During the following $\mathbf{9 0}$ minutes the runs of ventricular tachycardia continued and the blood pressure dropped to $80-90 \mathrm{mmHg}$ systolic. A levarterenol infusion of $1.3 \mathrm{mg}$ in $100 \mathrm{ml} 5 \%$ glucose solution was slowly started. One and a half hours after the administration of bretylium, following a bout of ventricular tachycardia, ventricular fibrillation occurred. External defibrillation was ineffective and external cardiac massage was begun. I.P.P.B. via an endotracheal tube with $100 \%$ oxygen was used. The patient was given $1 \mathrm{~g}$ calcium chloride, $160 \mathrm{mEq}$ sodium bicarbonate, and $500 \mathrm{ml}$ trometamol $0.3 \mathrm{M}$ intravenously and the rate of levarterenol drip was markedly increased. Ventricular fibrillation lasted for a few minutes and then asystole supervened. External massage was continued. Ten minutes later slow idioventricular rhythm reappeared, and the blood pressure rose spontaneously to $100 \mathrm{mmHg}$ systolic. External massage was discontinued temporarily. A slow rise in venous pressure from $22 \mathrm{~cm} \mathrm{H}_{2} \mathrm{O}$ and a gradual drop in left atrial pressure from $25 \mathrm{~cm} \mathrm{H}_{2} \mathrm{O}$ were noted. Concomitant with these changes, arterial pressure dropped again despite the generous use of levarterenol. Three hours later the central venous pressure had risen to $42 \mathrm{~cm} \mathrm{H}_{2} \mathrm{O}$ and the left atrial pressure had dropped to $5 \mathrm{~cm} \mathrm{H}_{2} \mathrm{O}$. Unassisted systemic blood pressure was at that time $50 \mathrm{mmHg}$ systolic. Isoproterenol drip $(1.6 \mathrm{mg}$ in $100 \mathrm{ml} 5 \%$ glucose with $0.8 \mathrm{~g} \mathrm{KCl}$ ) was added with no effect. On the assumption that the haemodynamic changes described above were due to right ventricular failure, the patient received $0.8 \mathrm{mg}$ deslanoside intravenously, but with no effect on the blood pressure. Respiration was controlled throughout by a respirator delivering $100 \%$ oxygen.

'New York Heart Foundation 
During the whole period of hypotension, approximately four hours, external cardiac massage was carried out intermittently, raising the blood pressure to $80-90 \mathrm{mmHg}$ systolic (as measured by direct radial artery cannulation). Each cessation of the massage was followed by a gradual drop in blood pressure, and the massage had to be restarted. The patient became cold and cyanotic and was anuric but remained awake. Central venous pressure remained steady above $40 \mathrm{~cm} \mathrm{H}_{2} \mathrm{O}$ and left atrial pressure was below $5 \mathrm{~cm} \mathrm{H}_{2} \mathrm{O}$. An arterial blood sample was analysed at that time as follows: $\mathrm{pH} 7 \cdot 19, \mathrm{PcO}_{2}$ $17 \mathrm{mmHg}$ actual bicarbonate $6 \mathrm{mEq} / 1$, base excess $21 \mathrm{mEq} / 1$, and $\mathrm{PO}_{2} 380 \mathrm{mmHg}$. It was decided that further buffer correction of the metabolic acidosis could not be successful without improving peripheral perfusion, and therefore $10 \mathrm{mg}$ chlorpromazine were given intravenously, resulting in immediate improvement in the patient's peripheral perfusion. She became pink and alert and started to pass urine. Blood pressure rose to $100 \mathrm{mmHg}$. Within 24 hours all supportive treatment could be discontinued and she made a slow and uneventful recovery. She is now 18 months post surgery and in excellent condition.

CASE 4 A 54-year-old woman suffering from mitral stenosis was admitted to hospital for heart surgery. Following acute embolism to the right femoral artery (the embolus was successfully removed) open mitral valvotomy was performed. Under cardiopulmonary bypass the patient underwent the operative procedure (the mitral valve orifice was dilated from $8 \mathrm{~mm}$ to $28 \mathrm{~mm}$ ) without complication.

Twenty-four hours after surgery she developed bouts of ventricular extrasystoles and received bretylium tosylate intramuscularly $(5 \mathrm{mg} / \mathrm{kg}$ body weight). Four hours after the administration of the drug, despite isoproterenol infusion, her blood pressure dropped to $50 \mathrm{mmHg}$ systolic and cardiac arrest in asystole soon followed. Resuscitation was immediately started and included external cardiac massage, I.P.P.B. via an endotracheal tube with $100 \%$ oxygen, intravenous infusion of $180 \mathrm{mEq} \mathrm{NaHCO}, 500 \mathrm{ml}$ trometamol $0.3 \mathrm{M}$, and a continuous levarterenol drip of $1.3 \mathrm{mg}$ in $100 \mathrm{ml} 5 \%$ glucose solution. Ten minutes later a rapid supraventricular rhythm appeared, but the blood pressure did not rise above $50 \mathrm{mmHg}$ systolic. A drip of $1.6 \mathrm{mg}$ isoproterenol in $100 \mathrm{ml} 5 \%$ glucose was added but did not raise the blood pressure either. Consequently external cardiac massage had to be employed for two hours. Only after increasing the rate of the levarterenol drip to a very high dose (40 drops $/ \mathrm{min}$ ) did the blood pressure rise to $100 \mathrm{mmHg}$ systolic. The patient received approximately $\mathbf{4 0} \mathrm{mg}$ levarterenol during the following 24 hours. Not until 30 hours after the administration of bretylium could the levarterenol drip be discontinued without a drop in blood pressure. The patient made a slow but complete recovery. She is in very good condition 18 months after surgery.
CASE 5 A 31-year-old woman was admitted to $\stackrel{\overrightarrow{5}}{9}$ hospital because of rheumatic heart disease, mitral stenosis and insufficiency, atrial fibrillation, and progressive exertional dyspnoea. The mitral valve was $\frac{\bar{c}}{2}$ replaced using a no. 7 Kay-Shiley disc valve.

The postoperative course was complicated by a mediastinal infection followed by endocarditis caused क by Klebsiella. This was treated by local drainage $\overrightarrow{0}$ and systemic antibiotics. After three weeks of treatment the patient became afebrile and asymptomatic, $\vec{\omega}$ and after two additional weeks antibiotic treatment was stopped. Before discharge from hospital electric $\overrightarrow{\vec{x}}$ cardioversion was performed. This was carried out $\underset{\sim}{\sim}$ successfully and the patient was given a dose of $1.2 \mathrm{~g}$ quinidine daily for maintenance of sinus rhythm. Sixteen hours after the beginning of quinidine admini- $\vec{c}$ stration sudden ventricular fibrillation occurred. The 0

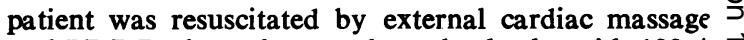
and I.P.P.B. through an endotracheal tube with $100 \% \overrightarrow{\vec{c}}$ oxygen; $300 \mathrm{ml}$ trometamol $0.3 \mathrm{M}$ were administered intravenously. The patient regained consciousness and the heart beat reverted spontaneously to atrial fibril. $\overrightarrow{0}$ lation. The blood pressure, measured directly via a radial artery cannula inserted early during the resuscitative effort, rose spontaneously to $100 \mathrm{mmHg}$ systolic after five minutes of cardiac massage. (The heart beat reverted spontaneously to atrial fibrillation.) Following this event of ventricular fibrillation the patient suffered $\stackrel{2}{\circ}$ recurrent attacks of ventricular tachycardia and $\stackrel{\mathbb{Q}}{\mathscr{Q}}$ fibrillation occurring at five-minute intervals for a $\underset{\vec{F}}{\overrightarrow{7}}$ period of about 16 hours. During the whole period $\frac{0}{3}$ a physician at the bedside watching the ECG and blood pressure curves on the oscilloscope was available for immediate resuscitation. This was carried out by electric shock and a variety of antifibrillatory drugs (intravenous lignocaine, $350 \mathrm{mg}$; phenytoin, 웅 $750 \mathrm{mg}$; procainamide, $300 \mathrm{mg}$; bretylium tosylate, $\ddot{x}$ $800 \mathrm{mg}$ ). These drugs, however, did not prevent the recurrence of ventricular fibrillation, and electric 3 shock (which was sometimes ineffective) was necessarily followed by external cardiac massage. The patient remained fully conscious the whole time. Urinary output was about $20 \mathrm{ml} /$ hour; acid-base 은 balance and blood gases were examined repeatedly $\frac{7}{0}$ using arterial blood samples and found to be satisfactory. After 16 hours of intermittent resuscitation $N$ events of ventricular fibrillation became less frequent, and after two additional hours the rhythm reverted $N$ to atrial fibrillation and no further ventricular arrhyth- N mias occurred. The patient was discharged from hos- 0 pital one week after her resuscitation asymptomatic and in good health. She is now 12 months post surgery and in excellent condition.

\section{DISCUSSION}

Provided the patient survives the operative and $\stackrel{2}{\mathbb{D}}$ the critical immediate postoperative period, the ultimate outcome of surgical treatment of rheumatic valvular disease is generally good. Severe 
cardiac arrhythmias and cardiac standstill are among the most important complications of this period.

There are very few reports of prolonged cardiopulmonary resuscitation following valvular replacement, and the reported results are uniformly bad. Jude et al. (1961) report the survival of two patients out of 21 resuscitative efforts post open heart surgery. Gilston (1965) reports the survival of 6 out of 18 patients in whom resuscitation was required postoperatively. In most of them the resuscitative effort was carried on for less than 15 minutes-the longest mentioned period being 80 minutes.

Among the patients who have undergone open heart surgery in our cardiac surgery unit and who had cardiac arrest postoperatively, five patients survived after prolonged repeated cardiopulmonary resuscitation. In four of the five cases described, a rigid prosthetic valve was inserted, double replacements having been carried out in two cases. The low profile Kay-Shiley disc valve was used in three cases and in the fourth a stented xenograft was used, while the fifth patient underwent open valvotomy. External cardiac massage in the presence of an implanted valvular prosthesis is deemed hazardous because of the possibility of rupture of coronary vessels (Burnside, Daggett, and Austen, 1970) or disruption of the valve (Wilcox, 1965). In our four patients with prosthetic valves, external massage produced no demonstrable damage to the heart or the prostheses. On the contrary, the competent prostheses only assured the haemodynamic effectiveness of the massage.

In all five cases direct arterial pressure, ECG, central venous pressure, and urinary output were continuously monitored. Direct arterial pressure measurements, easily visualized on a large oscilloscope, enabled assessment of the effectiveness of cardiac massage. In each of the five cases described, systolic blood pressure was maintained at about $100 \mathrm{mmHg}$ almost continuously throughout the external cardiac massage, which we assumed provided adequate perfusion. The virtual absence of post-cardiac massage complications in this group of patients is probably due to the fact that the massage could be carried out with the minimal force necessary to provide perfusion. It is noteworthy that all the operations were performed through a midline sternotomy incision and it is possible that this facilitates external massage without further damage to the chest cage. The intraarterial cannulae enabled frequent arterial blood samples to be obtained for blood gas and pH analyses. Metabolic acidosis was corrected accord- ingly by the administration of sodium bicarbonate and trometamol. The total amount of base used to correct the acidosis during the period of external cardiac massage was considerably less than that recommended by Gilston (1965). It may be concluded therefore that the adequate tissue perfusion obtained by the resuscitative measures accounted for the relatively small amount of buffer necessary. Furthermore, the conscious patients with a continuous output of urine during cardiac massage provided evidence of adequate cerebral and renal circulation. I.P.P.B. providing $100 \%$ oxygen through an endotracheal tube was begun immediately on all our patients and this seems to be a point of crucial prognostic importance (Safar, Brown, Holtey, and Wilder, 1961).

Comment should be made on two drugs used during resuscitation. Bretylium tosylate had recently been reintroduced to medical practice as a potent antiarrhythmic agent (Bacaner, 1968a, b). Its value was questionable in our patients, except in case 1 ; in fact, the severe fall in systemic pressure encountered in cases 3 and 4 may be attributed to the haemodynamic effects of the drug (Cotev et al., 1971). Case 3 showed evidence of extreme right ventricular failure. As chlorpromazine has been shown to lower pulmonary and systemic vascular resistance (Borman et al., 1971) it was administered in this case, with immediate marked improvement.

We attribute the successful outcome in these patients primarily to the immediate availability of a qualified physician and to cardiorespiratory and monitoring equipment at the bedside. An aggressive approach to cardiopulmonary resuscitation after open heart surgery is justified. A prolonged, stubborn effort should be expected from all concerned as long as vital signs are present.

\section{REFERENCES}

Ayers, W. R., and Doyle, J. T. (1962). Cardiopulmonary resuscitation. Review of one year's experience in a general hospital. N.Y. St. J. Med., 64, 1929.

Bacaner, M. B. (1968a). Treatment of ventricular fibrillation and other acute arrhythmias with bretylium tosylate. Amer. J. Cardiol., 21, 530.

(1968b). Quantitative comparison of bretylium with other antifibrillatory drugs. Amer. J. Cardiol., 21, 504.

Borman, J. B., Merin, G., Majblum, S., Milwidsky, H., and Cotev, S. (1971). The beneficial effects of chlorpromazine on pulmonary hemodynamics in patients after cardiopulmonary bypass. Ann. thorac. Surg., in press.

Burnside, J., Daggett, M. W., and Austen, W. G. (1970). Coronary artery rupture by a mitral valve prosthesis after closed chest massage. Ann. thorac. Surg., 9, 267.

Cotev, S., Merin, G., Stern, S., Milwidsky, H., and Borman, J. B. (1971). The hemodynamic effects of bretylium tosylate in patients after cardiopulmonary bypass. Unpublished data. 
Gilston, A. (1965). Clinical and biochemical aspects of cardiac resuscitation. Lancet, 2, 1039.

Head, L. R., Hudson, R. T., Head, J. M., and Head, J. R. (1962). Experiences with cardiopulmonary resuscitation. Arch Otolaryng., 76, 178

Jude, J. R., Kouwenhoven, W. B., and Knickerbocker, G. G. (1961). Cardiac arrest. Report of application of external cardiac massage on 118 patients. J. Amer. med. Ass., 178, 1063.

Kaplan, B. M., and Knott, A. P. Jr. (1964). Closed-chest cardiac massage for circulatory arrest; effectiveness in 100 consecutive cases. Arch intern. Med., 114, 5.

Klassen, G. A., Broadhurst, C., Peretz, D. I., and Johnson, A. L. (1963). Cardiac resuscitation in 126 medical patients using external cardiac massage. Lancet, 1, 1290.

Kouwenhoven, W. B., Jude, J. R., and Knickerbocker, G. G. (1960). Closed-chest cardiac massage. J. Amer. med. Ass., 173, 1064.
Lawrence, R. M., Haley, E. M., and Gillies, A. J. (1964). Closed-chest cardiopulmonary resuscitation. Results and criteria for application. N.Y. St. J. Med., 64, 2523.

Lillehei, C. W., Lavadia, P. G., DeWall, R. A., and Sellers, R. D. (1965). Four years' experience with external cardiac resuscitation. J. Amer. med. Ass., 193, 651.

Safar, P., Brown, C. T., Holtey, J. W., and Wilder, R. J. (1961). Ventilation and circulation with closed-chest cardiac massage in man. J. Amer. med. Ass., 176, 574.

Saphir, R. (1968). External cardiac massage. Prospective analysis of 123 cases and review of the literature. Medicine (Baltimore), 47, 73.

Wilcox, B. R. (1965). Disruption of a mitral-valve prosthesis, a complication associated with closed-chest cardiac massage. J. Amer. med. Ass., 194, 93. 